\title{
3D food printing as a promising tool for food fabrication: 3D printing of chocolate
}

\author{
${ }^{1,{ }^{*}}$ Sylvester, M., ${ }^{2}$ Bhandari, B. and ${ }^{2}$ Prakash, S \\ ${ }^{1}$ Department of Food Service, Faculty of Food Science and Nutrition, Universiti Malaysia Sabah, 88400, \\ UMS Kota Kinabalu, Sabah, Malaysia. \\ ${ }^{2}$ Department of Food Science, Faculty of Agriculture and Food Sciences, The University of Queensland, \\ Australia
}

\author{
Article history: \\ Received: 12 June 2020 \\ Received in revised form: 18 \\ August 2020 \\ Accepted: 19 August 2020 \\ Available Online: 27 \\ December 2020
}

\section{Keywords:}

$3 \mathrm{D}$ printed chocolate,

Infill pattern,

Infill percentage,

Texture modification

\section{DOI:}

https://doi.org/10.26656/fr.2017.4(S6).054

\begin{abstract}
The optimisation of printing dark chocolate was investigated, which included 3D printer modification. The modification comprises development of custom printer bed an inbuilt water recirculation system with a slow flow rate of $6.3 \mathrm{~mL} / \mathrm{s}$ to avoid vibration. Additionally, a fan was attached to enhance the solidification of chocolate. It was found that $32^{\circ} \mathrm{C}$ was the optimal condition of chocolate melting and this temperature was applied in the printing process. The addition of the support structure on the mechanical properties of chocolate such as cross and parallel support structures printed in a hexagonal shape was also investigated. Findings indicated that the cross support increased the stability and strength $(57.5 \pm 4.8 \mathrm{~N})$ of chocolate more than the chocolate printed with parallel support $(50.5 \pm 2.7 \mathrm{~N})$ and without any support structure $(12.6 \pm 6.1 \mathrm{~N})$. Different infill structures (infill pattern and percentage) can contribute to the textural modification of 3D printed chocolate. The appearance of the 3DP construction was vital as this modality can influence the acceptability of the product. Sensory analysis was conducted among $30 \mathrm{semi}$ -trained panellists. Most participants favoured the appearance of sample 3DP100\%_IP (1.33) to those of samples 3DP25\%_IP (2.00) and 3DP50\%_IP (2.67). On the textural perspectives, consumers indicated their potential preferences on chocolate printed with $25 \%$ infill percentage. Similar results from consumer paired-preference test were obtained. These results suggested that consumer realised the potential of $3 \mathrm{D}$ printing for textural modification.
\end{abstract}

\section{Introduction}

$3 \mathrm{D}$ printing is a layer-by-layer three-dimensional building process (Wegrzyn et al., 2012). The process operates in a similar way to printing on a paper from a word processor program on a personal computer, except that it is in $3 \mathrm{D}$. That is to say, in $2 \mathrm{D}$ printing, the image or text is printed row by row until it is complete across a length and width in a single layer (or a few layers in bold font function). However, the process of $3 \mathrm{D}$ food printing involves food-grade products such as sugar, starches, or protein to create an edible printed food (Zimmerman et al., 2012; van der Linden, 2015). In essence, printing food is done through the careful layering of tiny or thin semi-liquid food particles on top of each other to create a 3-dimensional novel processed food (Lam et al., 2002).

The early concept of 3D printing (3DP) was rapid prototyping (RP), the process of modelling, assembling and fabrication via computer-aided design (CAD) which was developed by Kodama from Japan in the late 1980s (3D Printing Industry, 2014). RP technology evolved into Additive Manufacturing (AM) which is a more advanced form that can construct intricate $3 \mathrm{D}$ objects layer-by-layer, either by using plastic polymer filaments, metal and, more recently, edible materials such as sugar and chocolate (Sher and Tutó, 2015). 3D printing has begun to emerge in food production and 3D food printers have been designed specifically for food fabrication. According to Gibson et al. (2010) apart from RP, there are some broadly used technologies in AM which are stereolithography (SL), FDM and selective laser sintering (SLS). According to Sun et al. (2015) there are a number of research studies and projects in 3D food printing in many areas which range from the development of conceptual ideas to an in-depth understanding of material properties. 
Chocolate is a complex composition that contains cocoa solids, milk solids, sucrose and lecithin. Altogether, these ingredients influence the rheological properties which are an important parameter for determining the printability of chocolate. The most important component in chocolate is the complex crystal structure of fat. There are six crystal polymorphs existing in chocolate (Afoakwa, 2010). These crystals have different ranges of melting points from $16.1^{\circ} \mathrm{C}$ up to 36.8 ${ }^{\circ} \mathrm{C}$ (Talbot, 2009). However, the most favourable crystal that gives chocolate its quality attributes such as smoothness, a glossy look and snap ability is Form V $(\beta)$ with a melting point of $33.8^{\circ} \mathrm{C}$ (Afoakwa, 2010). The solidification temperature (usually the same as the melting temperature of the $\beta$-crystal type) is an important material property that determines the feasibility of layerby-layer printing. The printed layer needs to quickly solidify to hold the subsequent printed layer. Therefore, having a cool printer bed is particularly important in the 3D printing of food materials such as chocolate.

Some of the 3D printers that are available in the market are not equipped with a cooling bed system. However, for substances like chocolate, to maintain the bed temperature, a cooling system such as cold water circulation is needed to ensure the printer bed will remain cool. It should be noted that a cold bed temperature can also lead to condensation of moisture on the bed because the surrounding air may reach the dew point temperature when it hits the cold bed. Thus, to avoid moisture condensation, it is also important that there is sufficient airflow around the printer bed.

Altering structural properties in designing food to modify the textural properties such as infill structure is relatively new in the $3 \mathrm{D}$ food printing field. There were reports on designing internal structure of $3 \mathrm{D}$ constructs in order to modify the textural properties of the printed foods. Liu et al. (2018) investigated the textural and structural quality of mashed potato (soft material) by modifying infill percentage $(10 \%, 40 \%, 70 \%$ and $100 \%)$ with different infill patterns (rectilinear, honeycomb and Hilbert curve) and variation in shell perimeters (3, 5 and 7 shells). They reported that firmness values $25.15 \mathrm{~g}$ to $144.81 \mathrm{~g}$ and Young modulus (487.99 $\mathrm{Pa}$ to $43,306.50$ $\mathrm{Pa}$ ) increased and solely affected by variation in infill density between $10 \%$ and $70 \%$. This indicates that an increase in infill percentage will increase the mechanical strength (firmness and Young modulus) of the 3D printed mashed potato. Severini et al. (2016) reported that the addition of an inner support structure (cross and parallel) was essential to hold the 3D printed cerealbased product for post-processing to make the constructs more stable. In this case, the infill structure was mainly designed to aid the stability of the construct.
Recently, the acceptance of 3D printed food has been studied in various settings and among targeted consumers. Brunner et al. (2018) explored Swiss consumers' attitudes and attitudinal changes toward 3D printed food using a survey. The questionnaire was constructed with 14 predictors, constituting variables of food neophobia, benefits perception, nutritional knowledge, previous knowledge and technology neophobia (Brunner et al., 2018). After an intervention which consisted of the feedback from the respondents, they reported that its outcome was successful in overcoming consumers' food neophobia and convincing consumers that 3DFP technology is capable of producing healthy and individualised meals with exciting food design. Although the advantages and numerous possible uses of 3D food printing are already widely discussed (Sun et al., 2015; Izdebska and Zolek-Tryznowska, 2016; Godoi et al., 2016; Mantihal et al., 2019), very little research has been conducted on consumers' attitudes, perceptions and acceptances toward food produced by $3 \mathrm{D}$ printing Therefore, this study aimed to demonstrate the capability of 3DFP to modify food texture by altering the internal structures of printed chocolate. A sensory evaluation of texture-modified 3D printed chocolate was conducted among 30 semi-trained respondents to assess consumers' preferences concerning sensory attributes such as texture and appearance and their overall preferences.

\section{Materials and methods}

\subsection{Materials}

Two types of dark chocolates, Cadbury dark chocolate (Choc-1) and Callebaut dark chocolate buttons (Choc-2) purchased locally in Brisbane, Australia was used in this study. Choc-1 was also used for cast chocolate samples as a control. The composition of the Cadbury dark chocolate was 53\% (minimum) cocoa solids, $35 \%$ (minimum) cocoa butter, $0.5 \%$ lecithin and approximately $11.5 \%$ sugar. The Callebaut dark chocolate buttons (bittersweet flavour, Lindt Piccoli) were composed of $58 \%$ (minimum) cocoa solids, 33\% (minimum) cocoa butter, 5\% anhydrous milk fat, $0.5 \%$ lecithin and vanilla and about 3.6\% sugar. Both dark chocolate samples (Choc-1 and Choc-2) were ground separately into powder in a controlled temperature room at around $\sim 5^{\circ} \mathrm{C}$ and kept in refrigeration $\left(\sim 8^{\circ} \mathrm{C}\right)$ separately until the initiation of the printing process.

\subsection{Commercial dark chocolate casting process}

Casting of Choc-1 was done to compare it with the textural property of $3 \mathrm{D}$ printed chocolate. Before casting, the chocolate was melted at a controlled temperature at around $32^{\circ} \mathrm{C}$ using a chocolate melting machine 
(ChocEdge, UK). Melted chocolate samples (10 g) were poured into a $3 \mathrm{D}$ printed cast (printed using Acrylonitrile butadiene styrene (ABS) filament (Figure 1)) and covered by a thin layer of clear food grade plastic wrap. All samples were kept under refrigeration at around $8^{\circ} \mathrm{C}$ until the initiation of the textural analysis and sensorial evaluation.

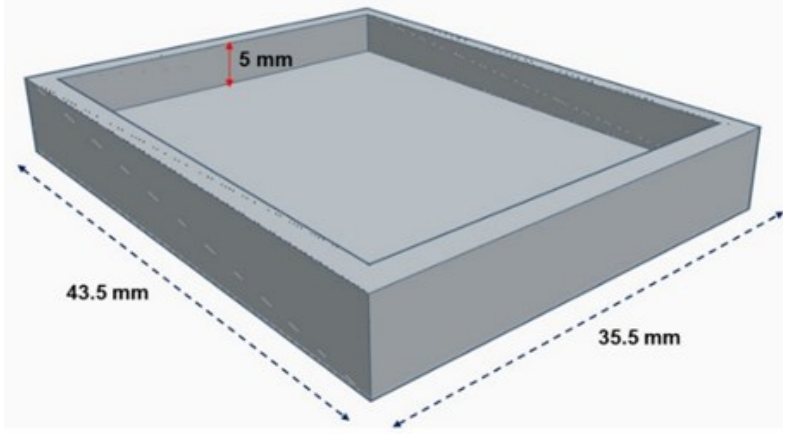

Figure 1. The 3D cast printed using Da Vinci 2.0 dual nozzle model XYZ printer with ABS filament.

\subsection{Printing process}

The 3D chocolate printing consisted of three essential steps: (i) making the 3D geometry design, (ii) slicing the design and (iii) the printing process.

\subsubsection{D geometry design}

Chocolate Model (1) of $20 \mathrm{~mm}$ x $50 \mathrm{~mm}$ and $5 \mathrm{~mm}$ thickness and Chocolate Model (2) of $43.5 \mathrm{~mm}$ x 35.5 $\mathrm{mm}$ and $5 \mathrm{~mm}$ thickness were designed (Figure 2) and the Hexagon design consist of $20.0 \mathrm{~mm}$ height and $20.0 \mathrm{~mm}$ width design with support structure Cross and parallel (Figure 3) using TinkerCad online software.

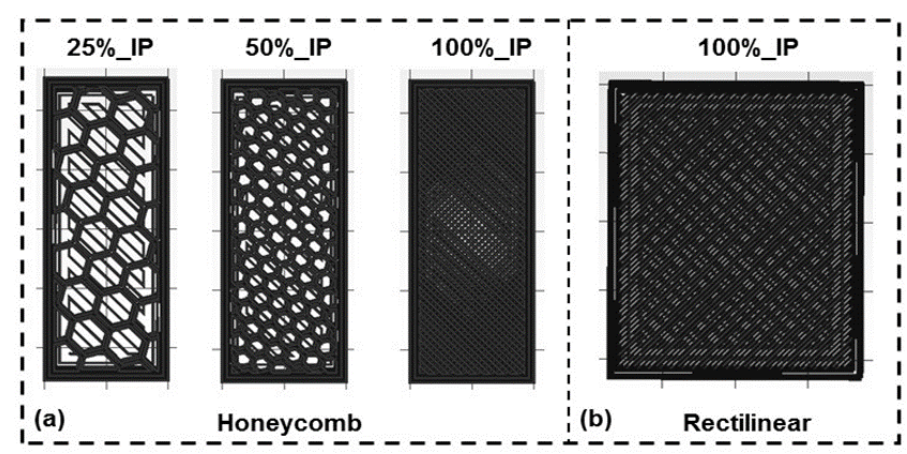

Figure 2. 3D model designs of rectangular shape (a) Model -1 (20 $\mathrm{mm}$ x $50 \mathrm{~mm}$ and $5 \mathrm{~mm}$ thickness) with Honeycomb pattern in variation of infill density of $25 \%$ IP, $50 \%$ IP and 100\%_IP (b) Model-2 (43.5 $\mathrm{mm} \mathrm{x} 35.5 \mathrm{~mm}$ and $5 \mathrm{~mm}$ thickness) in rectilinear pattern with $100 \%$ IP. IP refers to infill percentage.
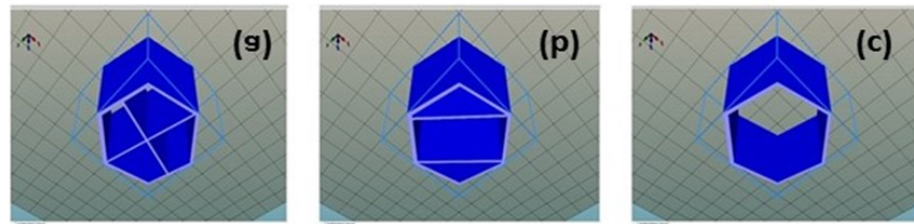

Figure 3. 3D model design of hexagonal model with (a) cross support (b) parallel support (c) no support.

\subsubsection{Slicing}

The 3D models from the above online software were uploaded into the Repetier-Host software (.stl file) and sliced using Sli3er configuration to generate the g-code for each model. The shell perimeters were set at default three shells (approximately $\sim 2.34 \mathrm{~mm}$ thickness) considering the inner nozzle diameter is $0.78 \mathrm{~mm}$. Figure 2 illustrates the 3D chocolate samples design for sensory analysis Model (1) for Choc-2 was set to a honeycomb infill pattern with a variation of infill of $25 \%, 50 \%$ and $100 \%$ as shown in Figure 2. Model (2) for Choc-1 was set to a rectilinear pattern with $100 \%$ infill to mimic the commercial chocolate block. Figure 3 represent the design models of hexagon shape custom with internal supports, cross, parallel and no support for mechanical strength analysis. All samples were sliced (with the specific g-code extracted for each 3D model) according to each infill pattern and infill percentage using Sli3er software.

\subsection{Operational conditions}

Porimy 3D chocolate printer (Porimy Co. Ltd, Kunshan, China) was used in this study. Prior printing, the extruder temperature was set at $32^{\circ} \mathrm{C}$ for 5 mins to ensure extruding temperature are controlled and maintained. Printing parameters were set as follow: printing speed $70 \mathrm{~mm} / \mathrm{s}$, extrusion temperature calibrated at $32^{\circ} \mathrm{C}$, nozzle size $1.5 \mathrm{~mm}$ (inner diameter $0.8 \mathrm{~mm}$ ) and printer bed temperature maintained at $15^{\circ} \mathrm{C}$ to $22^{\circ} \mathrm{C}$. These parameters were set based on correlations between thermal and flow behavior of the chocolate (Mantihal et al., 2017). Figure 4 illustrates the schematic diagram of the $3 \mathrm{D}$ printing mechanism which uses a rotary screw extrusion method to extrude chocolate. This printer automatically regulates the proper gap between nozzle and printer bed by means of a built-in Reprap XYZ system (a 3D printing system that navigates printer movement). The printed samples were stored in refrigeration at around $15^{\circ} \mathrm{C}$ until quality assessment

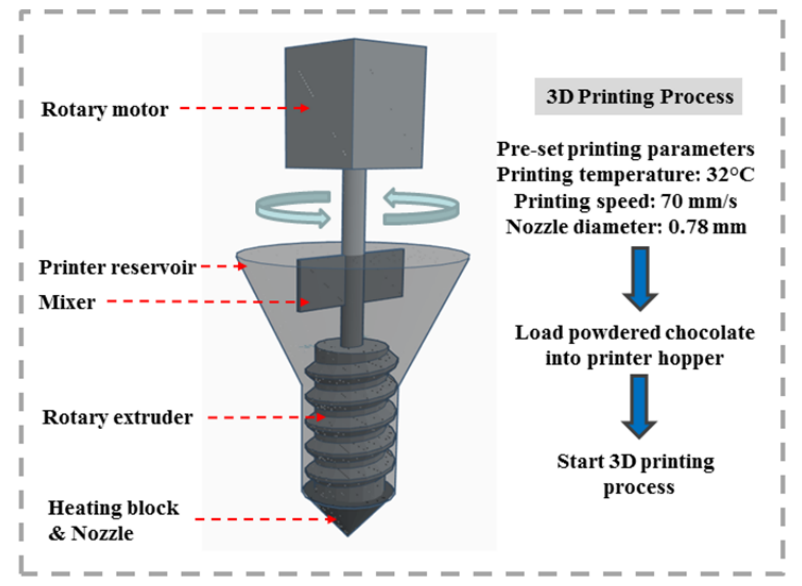

Figure 4. Schematic diagram of Porimy 3D chocolate printer and its printing mechanism. 
analysis.

\subsection{Dimensional and weight measurement of $3 D$ printed chocolates}

A digital calliper $(0-150 \mathrm{~mm}, \quad$ CraftRight $\AA$, Bunnings, Australia) was used to measure the dimensions of the 3D printed chocolate (length, width and thickness). This was done in three different positions on each printed chocolate samples for accuracy and the average value $(\mathrm{mm})$ was reported. Also, a digital weighing balance was used to assess the weight of each printed chocolate sample.

\subsection{Texture properties of $3 D$ printed chocolate}

The texture attribute of hardness was obtained by texture analysis using a texture analyser (Model TA-XT Plus, Stable Microsystem, UK) equipped with a $10.0 \mathrm{~kg}$ load cell with Exponent version 6.1.9.0 software. A TA42 knife blade was used and the test was conducted at room temperature (around $23^{\circ} \mathrm{C}$ ). Compression mode was used to analyse the samples at $10 \mathrm{~mm}$ distance. A pre-test of the speed of $1.0 \mathrm{~mm} / \mathrm{s}$ and the test speed of $2.0 \mathrm{~mm} / \mathrm{s}$ with $5.0 \mathrm{~g}$ trigger force were applied. The measurement was conducted in triplicate and the data of maximum force $(\mathrm{N})$ from the force-displacement curve were extracted.

\subsection{Sensory evaluation}

The sensory profile of the printed chocolate was carried out to determine consumer acceptability of 3D printed chocolate. The chocolate was evaluated using a ranking test for preferences and a paired-preferences test with the aid of RedJade sensory evaluation software. The sensory test was conducted in a sensory analysis laboratory, at the School of Agriculture and Food Sciences (SAFS), the University of Queensland, Australia. Ethical clearance approval for this evaluation was granted by the Human Research Ethics Committee, University of Queensland. 30 semi-trained (panellist who familiar with chocolate testing) panellists composed of 21 females and nine males from the School were involved in the sensory test. The age range of the panellists was between 28 and 55 years. The printing time for each sample ranged from 3 to 5 mins, depending upon the sample's infill percentage. The chocolate samples were kept at room temperature $\left(23^{\circ} \mathrm{C}\right)$ before evaluation. Two sets of samples were served to the panellists, starting with three samples for a ranking test for preferences. Once the panel completed the ranking test, the second set of samples ( 2 samples) for the paired preference test was given to the panellists.

For the ranking test for preferences, three dark chocolate (Choc-2) samples were prepared with dimensions of $20 \mathrm{~mm} \times 50 \mathrm{~mm}$ and $5 \mathrm{~mm}$ thickness, printed in honeycomb infill pattern with infill percentages of $25 \%, 50 \%$ and $100 \%$. The sensory attributes assessed were appearance, hardness and overall preferences using Rank 1 for the most preferred, Rank 2 for the medium ranking and Rank 3 for the least preferred. The printed samples were coded with three random numerical numbers and placed in random order on one paper plate for each respondent. For the pairedpreferences test, two dark chocolate (Choc-2) samples were served (dimensions: $43.5 \mathrm{~mm} \times 35.5 \mathrm{~mm}$ and $5 \mathrm{~mm}$ thickness). One sample was printed in $100 \%$ infill with a rectilinear pattern and another was the cast chocolate block. The samples were coded with three random digits and served randomly on the plate. In this test, the panellist had to choose which chocolate they preferred the most.

\subsection{Statistical analysis}

Dimensional properties (weight, width, length and thickness) and mechanical strength (Force $-\mathrm{N}$ ) were presented as mean values \pm standard deviation. Minitab version 17 (statistical software) was used to analyse the significant difference between values using the one-way analysis of variance (ANOVA) Tukey's test (where applicable). The significant difference was determined at $p$-value $(p)$ of less than 0.05 . The ranking of preferences (sensory analysis) was compared using a nonparametric, Friedman test.

\section{Results and discussion}

3.1 Modification of printer bed and development of cold water circulation system

A square $(200 \mathrm{~mm} \times 200 \mathrm{~mm} \times 10 \mathrm{~mm})$ stainless steel printer bed was designed to address the solidification issue of chocolate. The first layer of extrusion supports any subsequent layers as the printer builds up the structure. The printer bed was designed with inner water circulation to allow faster solidification of the extruded chocolate, by maintaining the bed temperature $\sim 16^{\circ} \mathrm{C}$. In addition, the temperature of the printer bed can also be set even cooler by circulating colder water. Figure 5 illustrates the cooling printer bed.
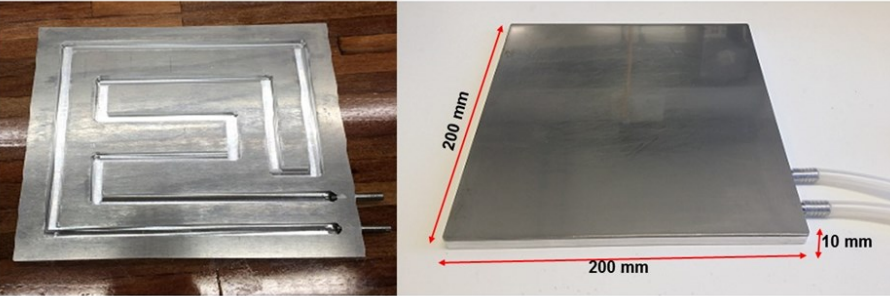

Figure 5. Cooling printer bed made in this study. The recirculation tubes (diameter $0.8 \mathrm{~cm}$ total $80 \mathrm{~cm}$ length) are enclosed as heat exchanger inside the plate. 
In order to cool the printer bed, a customized cold water circulation system was developed. Coldwater flowed at low pressure with a $12 \mathrm{~W}$ water pump to reduce the vibration on the bed during printing. It was designed with a water inlet and outlet for water inflow and outflow via an $8 \mathrm{~mm}$ diameter silicon tube. Figure 6 shows the cold water circulation system.

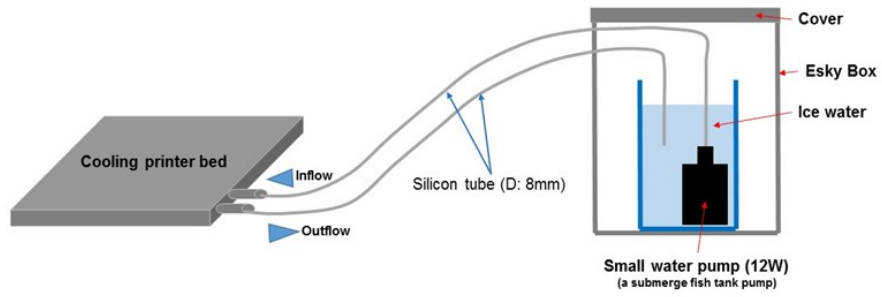

Figure 6. Schematic diagram of water circulation system with a $12 \mathrm{~W}$ submerged pump.

The volumetric flow rate was calculated using the formula: $Q=V / t$ where $Q$ is volumetric flow rate, $V$ is volume in $\mathrm{mL}$ and $t$ (time) is in seconds. An average volume $(\mathrm{mL})$ of $380 \mathrm{~mL}$ was collected in the volumetric flask in 60 seconds. The flow rate $(Q)$ was thus $6.33 \mathrm{~mL} /$ s. A low flow rate of cold water is important in this study to avoid vibration during water circulation as this may interrupt the chocolate printing process. The printer bed temperature was measured as $\sim 16^{\circ} \mathrm{C}$ during the printing process. Ice was added after every 30 mins of printing time to ensure the printer bed maintained the required temperature. The complete modified $3 \mathrm{D}$ printer is depicted in Figure 7.

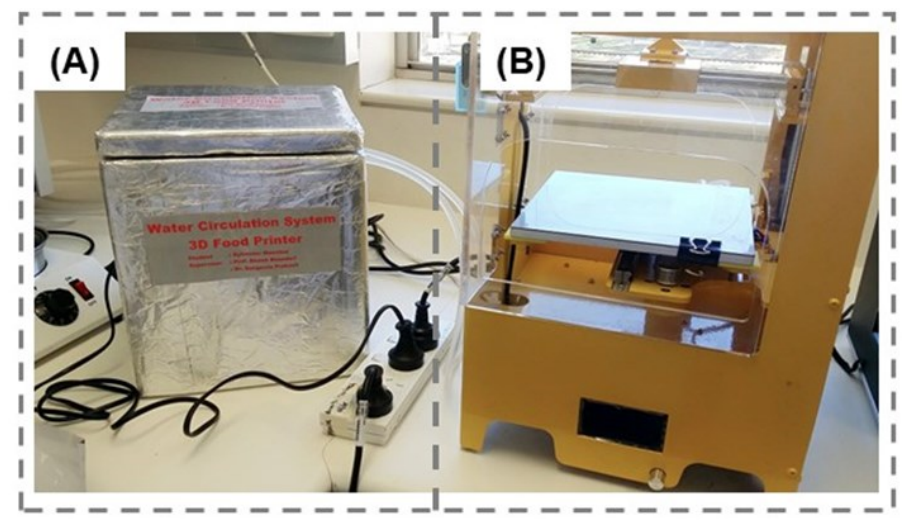

Figure 7. 3D chocolate printing system with additional feature (a) water circulation system (b) custom printer bed.

\subsection{Printer bed stabiliser (support)}

The acrylic printer bed of the Porimy 3D printer is a stainless steel bed. Hence new supports were devised to stabilize the bed. Four printer bed stabilizers (Figure 8) were developed through $3 \mathrm{D}$ design and printed using XYZ printing via a Da Vinci 2.0 filament 3D printer. A square block with $38 \mathrm{~mm} \times 34 \mathrm{~mm} \times 4 \mathrm{~mm}$ (medium infill 25\%) was printed with ABS filament with $7 \mathrm{~mm}$ diameter hole at the centre for ease of attachment on the printer. It was observed that the custom printer bed stabilizer was able to support the stainless steel printer bed.

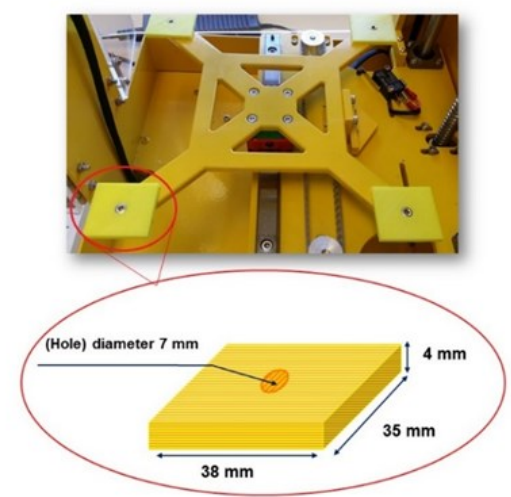

Figure 8. Printer bed support printed using 3D filament printer (XYZ printing) with ABS filament.

\subsection{Addition of air blowing fan}

During the printing process, the air was blown toward the deposited chocolate using a fan, which assisted in speeding up the solidification process as the 3D construction's height is built. Each layer needed to solidify quickly to support the upcoming layer to avoid the structure from collapsing. In addition, air from the fan also helped to reduce the condensation on top of the printer bed as water droplet formation may occur while the printer bed is cooled depending on the temperature used and the humidity of the ambient air. Figure 9 shows the fan (USB Fan $2.25 \mathrm{~W}$ ) attached to the printer. Airflow rate was not measured.

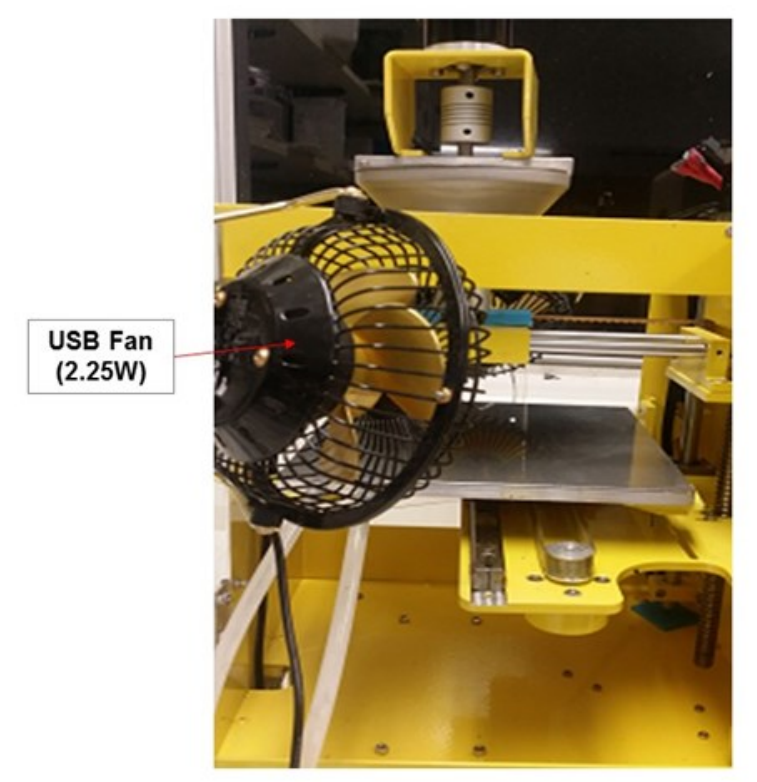

Figure 9. Attachment of USB fan $(2.25 \mathrm{~W})$ on the 3D Porimy printer.

\subsection{Optimization of nozzle height}

Nozzle height is defined as the gap between the nozzle tip and deposited top layer on the printer bed. Attalla et al. (2016) reported that the nozzle distance 

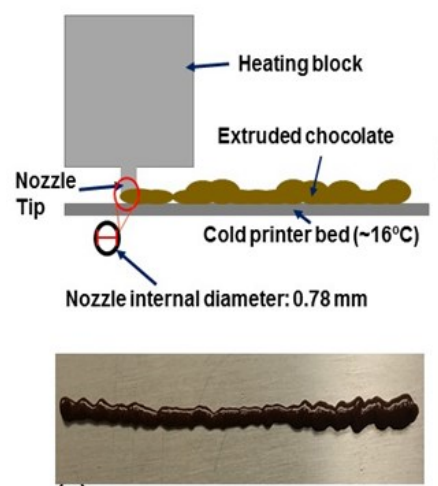

(a) Diameter (0.98 $\min -1.90 \mathrm{max})$
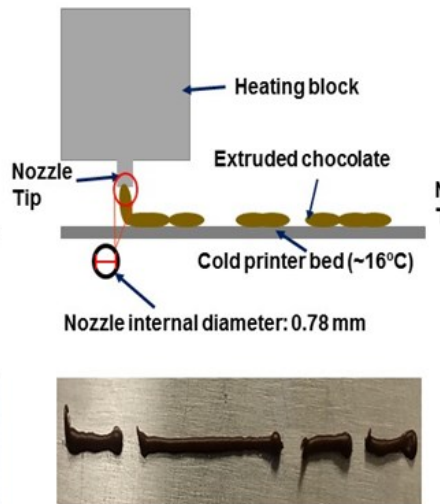

(b) Diameter (0.92 $\min -1.21$ max)

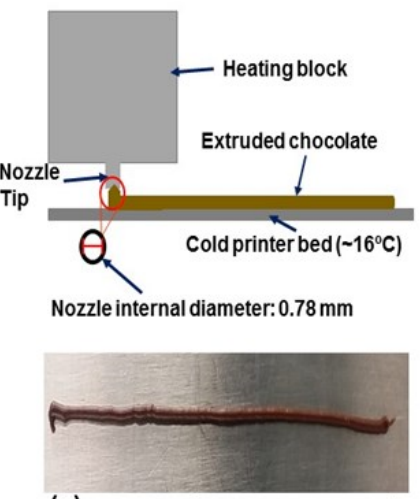

(c) Diameter (0.74 min - 0.79 max)

Figure 10. Schematic illustration of effect of distance between nozzle tip and printer bed [unit measurement for diameter in $\mathrm{mm}$, nozzle size $0.78 \mathrm{~mm}$, printing speed $70 \mathrm{~mm} / \mathrm{s}$, printer bed temperature $\sim 16^{\circ} \mathrm{C}$ and nozzle height (a) $0.5 \mathrm{~mm}$ (b) $1.0 \mathrm{~mm}$ (c) 0.78 $\mathrm{mm}]$.

could influence the geometry shape of a $3 \mathrm{D}$ printed product. Theoretically, the extrusion mass flow rate and the movement speed of the nozzle assumed to directly influence the nozzle height and would result in a bed of extruded material with a diameter equal to that of the nozzle (Khalil and Sun 2007). Ideally, the extruded chocolate should have the same diameter as the nozzle size considering no swelling, shrinking or expansion of the extruded material (Yang et al., 2018). Many trials were done in this study to determine the accurate nozzle height suitable for chocolate extrusion. In this experiment, a small nozzle with an inner diameter 0.78 $\mathrm{mm}$ were used. Periard et al. (2007) suggested that a small nozzle diameter helps to construct a fine resolution and a smooth 3D object. Three extruded first layers with varied nozzle height settings are shown in Figure 10.

A thicker extruded line (diameter 0.98 min - 1.90 $\max$ ) than anticipated was obtained with a nozzle height $0.5 \mathrm{~mm}$ as shown in Figure 10(a). A broken extruded line (diameter $0.92 \mathrm{~min}-1.21 \mathrm{max}$ ) can be seen in Figure 10 (b) where the nozzle height was $1.0 \mathrm{~mm}$. The best extruded line (diameter $0.74 \mathrm{~min}-0.79 \mathrm{max}$ ) considered to be almost equivalent with nozzle diameter size was observed in Figure 10(c) where the nozzle height was $0.78 \mathrm{~mm}$. Thus, we found that in chocolate extrusion, it was best that the nozzle height is the same as the nozzle diameter. This result was similar to that in a previous study (Yang et al., 2018).

\subsection{Mechanical strength of $3 D$ constructs as a function of support structure}

Snap quality is an important quality parameter of chocolate produce. The influence of supports on the snap force was determined using a texture analyser. In this experiment, only callebaut dark chocolate (Choc-2) were printed. Table 1 shows the mean value of force $(\mathrm{N})$ needed to break each sample. The force required to break the chocolate samples (based on diameter) were significantly different $(p<0.05)$. It was observed that the constructs with the cross support required a higher force to break the sample with $>56.00 \mathrm{~N}$ and had a high snap quality and firmer texture as compared to other sample designs. Sample with no support required less force to break the sample with a force of $<16.0 \mathrm{~N}$. Cross support structure enabled to hold the main angle of the chocolate geometry (Figure 11) keeping it firm and stable as compared to sample with parallel support and without support.

Table 1. Mean value of Force $(\mathrm{N})$ required to break chocolate sample according to the type of support.

\begin{tabular}{lccc}
\hline \multirow{1}{*}{ Supports } & \multicolumn{3}{c}{ Force $(\mathrm{N})$} \\
\cline { 2 - 4 } & $($ diameter & (diameter & $($ diameter \\
& $43.0 \mathrm{~mm})$ & $53.0 \mathrm{~mm})$ & $63.0 \mathrm{~mm})$ \\
\hline Cross Support & $56.91 \pm 7.4^{\mathrm{a}}$ & $57.48 \pm 4.8^{\mathrm{a}}$ & $58.42 \pm 4.4^{\mathrm{a}}$ \\
Parallel Support & $50.01 \pm 6.4^{\mathrm{a}}$ & $44.68 \pm 10.7^{\mathrm{a}}$ & $50.52 \pm 2.7^{\mathrm{a}}$ \\
No support & $11.63 \pm 3.1^{\mathrm{b}}$ & $12.61 \pm 2.5^{\mathrm{b}}$ & $15.84 \pm 5.0^{\mathrm{b}}$ \\
\hline
\end{tabular}

Values with different superscripts in the same row are significantly different at $p<0.05$.
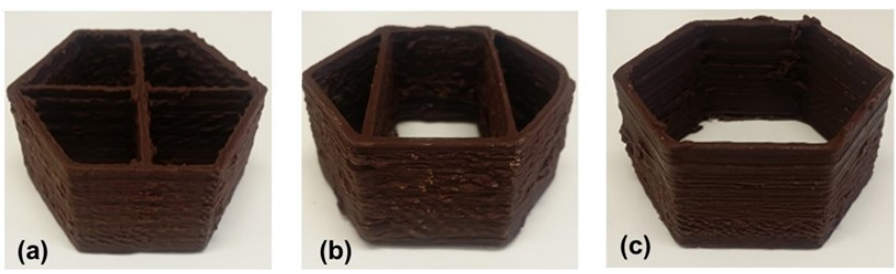

Figure 11. Three model designs of printed 3D chocolates (a) hexagonal shape with cross-support (b) hexagonal shape with parallel support (c) hexagonal shape with no support.

Figure $12 \mathrm{a}, 12 \mathrm{~b}$ and $12 \mathrm{c}$ illustrate steep curves with a short displacement indicating a good snap quality. However, a sample with diameter $43.0 \mathrm{~mm}$ (without support) in Figure 12c experienced a long and slow escalation signifying less snap quality and only small force $(11.63 \mathrm{~N})$ needed to snap the sample. The mechanical strength of commercial dark chocolate is significantly affected by the content of cocoa solid particles as reported by Nedomova et al. (2013). They 
reported that force $(\mathrm{N})$ required to break dark chocolate ( $70 \%$ cocoa solid content) was $40.0 \mathrm{~N}$ at crosshead speed $1 \mathrm{~mm} / \mathrm{min}$. In this study, cocoa solid content in the samples was constant $(58 \%)$ and the chocolate was printed with varied support structure and diameter. These variables also affected the mechanical strength of $3 \mathrm{D}$ printed dark chocolate. Beckett (2008) reported that a steep curve of maximum force and short displacement related to a good snap quality of chocolate. The addition of support structure has not only improved the snap property but also increased the stability printed product. This is important in designing complex 3D constructs, specifically creating higher constructs. Supports aid to hold and maintain the pre-determined shape. The ultimate aim of support structure is to stabilise the intricate structure and also to develop the texture of the food. Depending on the textural properties aimed, the number of support structure can be varied. Internal structures with different level of thickness and numbers on the textural properties of chocolate will be the subject of future studies. A comparison was carried out among three internal structure designs: (1) void space, (2) built parallel support and (3) built cross support. The arrangement of support structure whether parallel or cross support also determines the mechanical strength of 3DP object. It was demonstrated that cross support resulted in more stable 3D construct as per the higher force required to break the object during snap tests.

\subsection{D printed chocolate for sensory evaluation}

The 3D printed constructions and cast chocolate block for Choc-1 (Cadbury dark chocolate) and Choc-2 (Callebaut dark chocolate) are illustrated in Figure 13. As can be seen in the figure, the 3D printed chocolate constructed with various infill percentages $(25 \%, 50 \%$ and $100 \%$ ) were able to support the size and shape of the constructions. Also, the hollow structure was visible in chocolate printed in $25 \%$ and $50 \%$ infill when the chocolate was snapped. The textural and preferences of $3 \mathrm{D}$ printed chocolate are discussed in the subsequent section.

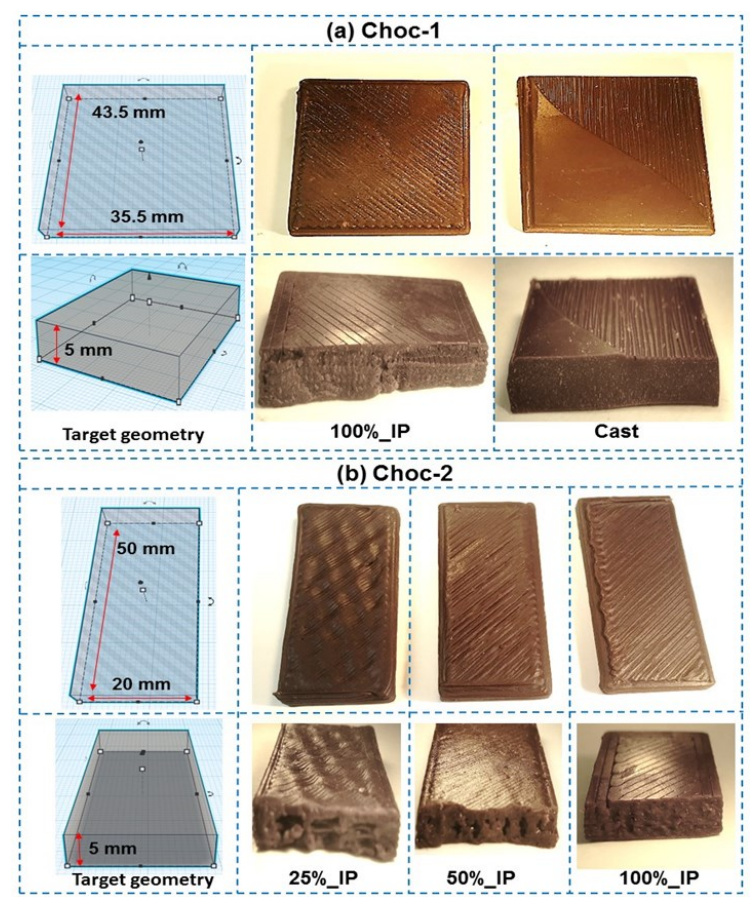

Figure 13. Representative images of 3D printed and cast chocolate samples - target geometry as reference. (a) Choc-1 is Cadbury dark chocolate - one sample was printed in $100 \%$ infill with rectilinear infill pattern and the other is a cast sample. (b) Choc-2 is the Callebaut dark chocolate printed in various infill percentages, 25\%, 50\% and 100\%, with a honeycomb infill pattern. IP means infill percentage.

\subsection{Evaluation of dimensional properties and weight of $3 D$ printed chocolate}

Table 2 shows the recorded thickness, width and length of the $3 \mathrm{D}$ constructs. As can be seen in Table 2, the thickness of the construction printed with Choc- 2 (regardless of infill percentages) remained the same; there was no significant difference $(p<0.05)$ between samples printed in $25 \%(5.09 \pm 0.03 \mathrm{~mm}), \quad 50 \%$ $(5.12 \pm 0.07 \mathrm{~mm})$ and $100 \% \quad(5.06 \pm 0.04 \mathrm{~mm})$, respectively. Also, the width and length of the constructions showed similarity to that of the predesign geometry, as there was no significant difference $(p<$ 0.05 ) between samples printed in $25 \%, 50 \%$ and $100 \%$ infills. Similarly, for samples printed with Cadbury dark chocolate (Choc-1), the thickness, width and length of the printed product $(100 \%$ infill) were not significantly
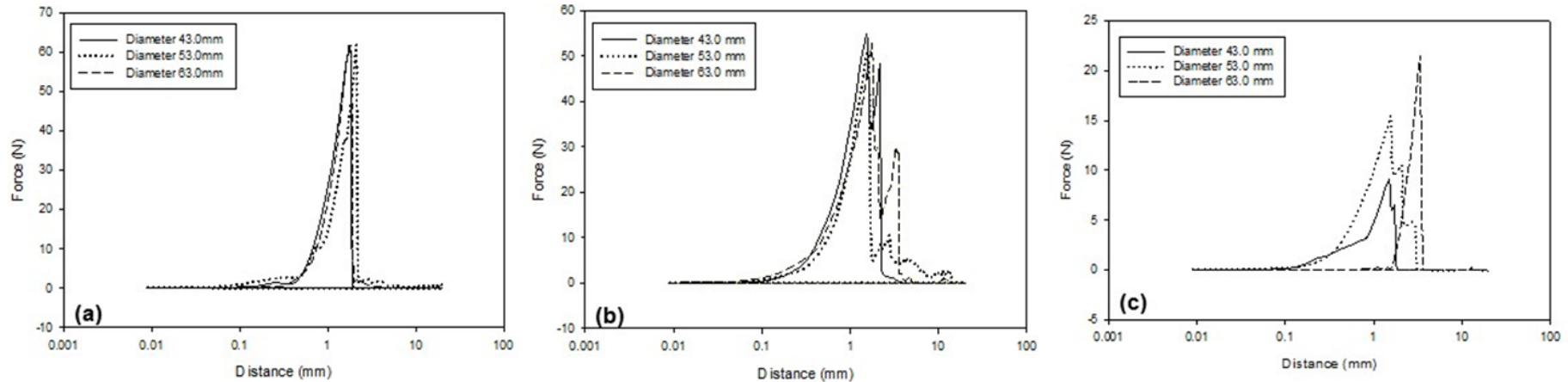

Figure 12. Force-distance curves measured by texture analyser of 3D printed chocolate with (a) cross support (b) parallel support (c) no support using break probe with a test speed $2.0 \mathrm{~mm} / \mathrm{s}$. 
Table 2. Recorded dimensional properties (thickness, width, length) and weight of 3D printed Choc-1 with $100 \%$ infill (rectilinear pattern) and cast samples and Choc-2 samples with infill of 25\%, 50\% and 100\% (honeycomb pattern).

\begin{tabular}{|c|c|c|c|c|c|c|}
\hline \multirow{2}{*}{\multicolumn{2}{|c|}{ Dimension }} & \multicolumn{2}{|c|}{ Choc-1 } & \multicolumn{3}{|c|}{ Choc-2 } \\
\hline & & $100 \%$ IP & Cast & $25 \%$ IP & $50 \%$ IP & $100 \%$ IP \\
\hline Thickness & $(\mathrm{mm})$ & $5.07 \pm 0.02^{\mathrm{a}}$ & $5.00 \pm 0.0^{\mathrm{a}}$ & $5.09 \pm 0.03^{\mathrm{a}}$ & $5.12 \pm 0.07^{\mathrm{a}}$ & $5.06 \pm 0.04^{\mathrm{a}}$ \\
\hline Width & $(\mathrm{mm})$ & $35.34 \pm 0.52^{\mathrm{a}}$ & $35.50 \pm 0.0^{\mathrm{a}}$ & $20.44 \pm 0.51^{\mathrm{a}}$ & $20.40 \pm 0.53^{\mathrm{a}}$ & $20.09 \pm 0.03^{\mathrm{a}}$ \\
\hline Length & $(\mathrm{mm})$ & $43.75 \pm 0.21^{\mathrm{a}}$ & $43.50 \pm 0.0^{\mathrm{a}}$ & $51.15 \pm 1.02^{\mathrm{a}}$ & $50.06 \pm 0.09^{\mathrm{a}}$ & $50.08 \pm 0.07^{\mathrm{a}}$ \\
\hline Weight & (g) & $9.21 \pm 0.52^{b}$ & $10.00 \pm 0.0^{\mathrm{a}}$ & $4.70 \pm 0.64^{c}$ & $6.03 \pm 0.21^{\mathrm{b}}$ & $8.39 \pm 0.65^{\mathrm{a}}$ \\
\hline
\end{tabular}

Values with different superscripts in the same row are significantly different at $p<0.05$. IP, infill percentage.

different $(p<0.05)$ with those of the cast chocolate block (see Table 2).

The dimensions of the cast chocolate block remain as per the predesign model because the chocolate was moulded explicitly to the predetermined dimensions. Similar results were reported by different authors for other 3D printed materials. Liu et al. (2018) reported that mashed potato constructions printed in $10 \%, 40 \%$ and $70 \%$ infill were closely matched to the design geometry. Also, Yang et al. (2018) designed an intricate geometry of Mickey Mouse with a predesign model (length 5.40 $\mathrm{cm}$, width $5.00 \mathrm{~cm}$ and height $2.30 \mathrm{~cm}$ ) using dough as the main substrate. They verified that $3 \mathrm{D}$ printing was able to re-create an intricate design precisely to that of the design geometry with the dimensions of $5.41 \mathrm{~cm}$ in length, $4.95 \mathrm{~cm}$ in width and $2.28 \mathrm{~cm}$ in height. These findings indicate that $3 \mathrm{D}$ food printing was capable of producing a product with accurate dimensions. Thus, the results suggest that this novel technology is a great tool for food customisation.

A significant difference $(p<0.05)$ was observed in the weight of each construction printed in various infill percentages: $25 \%(4.70 \pm 0.64 \mathrm{~g}), 50 \%(6.03 \pm 0.21 \mathrm{~g})$ and $100 \%(8.39 \pm 0.65 \mathrm{~g})$. Also, the weight of printed chocolate (Choc-1) was recorded as less than that of the cast chocolate block $(9.21 \pm 0.52 \mathrm{~g})$. The difference of weight between the $3 \mathrm{D}$ printed chocolate and cast samples is due to the layer-by-layer deposition method in the $3 \mathrm{D}$ printing process. In the printing process, the fusion between layers of chocolate will be formed by gravity, cohesive effects and the swell behaviour of extruded chocolate (Mantihal et al., 2019). Incomplete fusion of layers with their adjacent layers will cause micro-voids in the microstructure. These layers could be visually seen in the $3 \mathrm{D}$ printed chocolate. In comparison, the cast sample preparation involves filling the mould with molten chocolate to form a single solid and compact mass. Therefore, this difference in production influences the weight of the chocolate.

It is expected that increasing the infill percentage will increase the weight of the printed construction (Table 2). The increased weight is due to the amount of extruded material used to fill the construction to accommodate the preset infills (Severini et al., 2016). Fernandez et al. (2016) also reported that the weight of the constructs (ABS filament) significantly increased from $11.2 \mathrm{~g}$ up to $18.9 \mathrm{~g}$, respectively as the constructs were printed from $20 \%$ to $100 \%$ infill (with honeycomb infill pattern). These results confirm that a variation in infill percentage would strongly influence the $3 \mathrm{D}$ food construction's weight.

\subsection{Textural evaluation of $3 D$ printed and cast chocolate}

In this experiment, honeycomb infill pattern was applied as this criss-cross pattern provides strong support in 3D construction (Murphy and Atala, 2014; McLouth et al., 2017). Figure 14 exhibits of force $(\mathrm{N})$ as a function of distance $(\mathrm{mm})$ of chocolate printed with Choc-1 (with $100 \%$ infill and cast samples) and Choc-2 with a variation of infill percentages $(25 \%, 50 \%$ and $100 \%)$. Figure 14a clearly shows that the cast chocolate requires a higher force $(\mathrm{N})$ to break the samples than that of the 3D printed construction with $100 \%$ infill. In Figure 14b, a variation of force $(\mathrm{N})$ was observed as the infill percentage increased. A steep curve with slight displacement can be seen indicating a good snap quality of all the chocolate samples (Beckett, 2011; Mantihal et al., 2018).
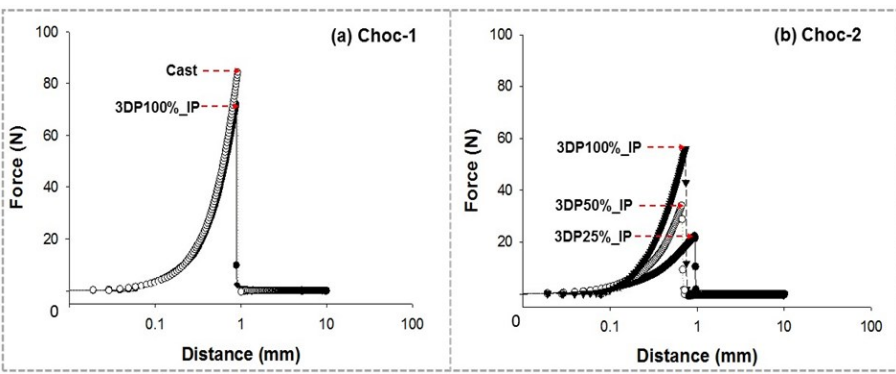

Figure 14. Representative graphs of force (N) as a function of distance $(\mathrm{mm})$ of 3DP chocolate printed and cast for samples (a) Choc-1 with $100 \%$ infill for 3DP (rectilinear pattern) and (b) Choc-2 samples various infill percentages of $25 \%, 60 \%$ and $100 \%$ (honeycomb pattern) with a pre-test speed of 1.0 $\mathrm{mm} / \mathrm{s}$ and test speed $2.0 \mathrm{~mm} / \mathrm{s}$ with $5.0 \mathrm{~g}$ of trigger load of all chocolate.

Table 3 summarises the force $(\mathrm{N})$ required to break chocolate samples printed with Choc-1 (with 100\% infill in a rectilinear pattern and cast samples) and Choc-2 (in $25 \%, 50 \%$ and $100 \%$ infill) in a honeycomb pattern. As 
Table 3. Recorded force $(\mathrm{N})$ to break the chocolate samples with various infill percentages $(25 \%, 50 \%$ and $100 \%)$ and cast samples.

\begin{tabular}{lccccc}
\hline & \multicolumn{3}{c}{ Choc-1 } & \multicolumn{3}{c}{ Choc-2 } \\
\cline { 2 - 6 } & $100 \% \_$IP & Cast & $25 \% \_I P$ & $50 \% \_$IP & $100 \%$ IP \\
\hline Force $(\mathrm{N})$ & $71.06 \pm 1.35^{\mathrm{b}}$ & $83.58 \pm 1.40^{\mathrm{a}}$ & $20.44 \pm 1.12^{\mathrm{c}}$ & $33.52 \pm 1.55^{\mathrm{b}}$ & $54.43 \pm 1.47^{\mathrm{a}}$ \\
\hline
\end{tabular}

Values with different superscripts in the same row are significantly different at $p<0.05$.

can be seen in Table 3, the 3D printed Choc-2 required an increase in the force $(\mathrm{N})$ to break the samples as the infill percentage increased. It was observed that chocolate printed with $25 \%$ infill required $20.44 \pm 1.12 \mathrm{~N}$, $50 \%$ required $33.52 \pm 1.55 \mathrm{~N}$ and $100 \%, 54.43 \pm 1.47 \mathrm{~N}$, respectively. The forces were significantly different at $p$ $<0.05$.

For Choc-1, there was also a significant difference ( $p$ $<0.05)$ in the force $(\mathrm{N})$ required to break the cast and $100 \%$ infill chocolate samples, $83.58 \pm 1.40 \mathrm{~N}$ and $71.06 \pm 1.35 \mathrm{~N}$, respectively. The reduced resistance to break the printed Choc-1 (3DP100\%_IP) is due to a weak interface of layers affected by the sequential layering upon printing. This result is also in line with Le Tohic et al. (2018) who reported that the hardness of the $3 \mathrm{D}$ cheese construction diminished by $\sim 49 \%$ compared to that of cast cheese. Therefore, cast samples are relatively tougher than printed constructions even when printed at $100 \%$ infill.

Also, an increase in percentage infill means that the intensity of deposited layers (mesostructure) becomes compact as the higher IP is achieved (Rankouhi et al., 2016). Figure 13 illustrates that a larger hollow structure can be seen in samples printed with $25 \%$ infills and this becomes compact when samples are printed in 50\% infill while no void was visible for samples printed in $100 \%$ infill. A similar concept was presented in a pectin-based food stimulant printed in honeycomb structure (Vancauwenberghe et al., 2018). The researchers reported that Young's modulus of printed samples with larger cell size was less $(11.58 \pm 1.43 \mathrm{kPa})$ than that of samples printed in a cube which was similar to printing in $100 \%$ infill $(118.58 \pm 12.10 \mathrm{kPa})$. Thus, by altering the infill percentage the texture of the printed construction will substantively change.

Based on the results of the textural properties testing of the 3D printed chocolate, we found an increase in the mechanical strength of $3 \mathrm{D}$ printed chocolate is correspondingly influenced by the variation of infill percentage. Overall, the texture (hardness) of 3D printed chocolate can be changed subject to internal structure modification. In the next section, we attempt to explore the sensorial properties of $3 \mathrm{D}$ printed dark chocolate through sensory evaluation and assessing consumer preferences.

\subsection{Sensory profile of $3 D$ printed chocolate}

The sensory profile of the printed chocolate was carried out to determine consumer acceptability of 3D printed chocolate. Two sets of samples were served to the panellists, starting with three samples for a ranking test for preferences. Once the panel completed the ranking test, the second set of samples ( 2 samples) for the paired preference test was given to the panellists. For the ranking test for preferences, three dark chocolate (Choc-2) samples were prepared with dimensions of 20 $\mathrm{mm} \times 50 \mathrm{~mm}$ and $5 \mathrm{~mm}$ thickness, printed in honeycomb infill pattern with infill percentages of $25 \%, 50 \%$ and $100 \%$. The sensory attributes assessed were appearance, hardness and overall preferences using Rank 1 for the most preferred, Rank 2 for the medium ranking and Rank 3 for the least preferred. The printed samples were coded with three random numerical numbers and placed in random order on one paper plate for each respondent. For the paired-preferences test, two dark chocolate (Choc -2) samples were served (dimensions: $43.5 \mathrm{~mm} \times 35.5$ $\mathrm{mm}$ and $5 \mathrm{~mm}$ thickness). One sample was printed in $100 \%$ infill with a rectilinear pattern and another was the cast chocolate block. The samples were coded with three random digits and served randomly on the plate. In this test, the panellist had to choose which chocolate they preferred the most.

The 3D printed constructions and cast chocolate block for Choc-1 (Cadbury dark chocolate) and Choc-2 (Callebaut dark chocolate) are illustrated in Figure 13. As can be seen in the figure, the 3D printed chocolate constructed with various infill percentages $(25 \%, 50 \%$ and $100 \%$ ) were able to support the size and shape of the constructions. Also, the hollow structure was visible in chocolate printed in $25 \%$ and $50 \%$ infill when the chocolate was snapped.

\subsection{Ranking for preference evaluation}

Table 4 presents the estimated median based on the Friedman test (nonparametric) and $p$-value for 3D printed dark chocolate samples (at $25 \%, 50 \%$ and $100 \%$ infill) in an evaluation of ranking for preferences in terms of appearance and hardness and overall preferences. As can be seen in Table 4, there was a significant difference $(p<0.05)$ between the preferred appearance of the 3DP samples (Choc-2) as most participants favoured the appearance of sample 
Table 4. Recorded median and p-value of ranking of preferences (appearance, hardness and overall preferences) based on Friedman test for 3DP chocolate printed in various infill percentages $(25 \%, 50 \%$ and $100 \%)$.

\begin{tabular}{lcccc}
\hline \multirow{2}{*}{ Ranking for preferences } & \multicolumn{3}{c}{ Samples } & \multirow{2}{*}{ p-value } \\
\cline { 2 - 5 } & 3DP25\%_IP & 3DP50\%_IP & 3DP100\%_IP & \\
\hline Appearance & 2 & 2.67 & 1.33 & $0.001^{*}$ \\
Hardness & 1.66 & 2 & 2.33 & 0.792 \\
Overall preferences & 1.33 & 2.66 & 2 & 0.875 \\
\hline
\end{tabular}

$* P<0.05$. Ranking varied from $1-3$ (1 is the most preferred sample)

$3 \mathrm{DP} 100 \%$ IP (1.33) to those of samples 3DP25\% IP (2.00) and 3DP50\%_IP (2.67). These results indicate that the participants mostly prefer the smooth appearance of the 3D printed chocolate (see Figure 13). As the infill structure is printed at closer to $100 \%$ infill, the infill structure provides sufficient support to the top layer and prevents it from any surface deformation (Mantihal et al., 2018). Thus, a smooth and even top layer is produced as the infill percentage increased. The appearance of the 3DP construction was vital as this modality can influence the acceptability of the product.

There were no significant differences $(p>0.05)$ in the participants' preferred texture (hardness) among the 3DP samples. However, participants indicated their preferences for the hardness of chocolate sample (by bitting the 3D printed chocolate) $3 \mathrm{DP} 25 \%$ IP (1.66) as compared to 3DP50\%_IP (2.00) and 3DP100\%_IP (2.33). This result corroborates with the finding in Section 7.3.2, indicating that samples printed in $25 \%$ infill are less hard than samples printed in $50 \%$ and $100 \%$ infill. In this case, we found that the participant is likely to choose a modified texture (less hard). The way the texture changes is significant in determining food product acceptance (Jeltema et al., 2016) and 3DP provides freedom to customise a design, modify textures and alter palatibility (Szczesniak, 2002; Devezeaux de Lavergne et al., 2016; Dankar et al., 2018)

In terms of overall preferences, no significance difference $(p>0.05)$ was found among all 3D printed chocolate (Choc-2) samples with different infill percentages. The decision about overall preferences is based on the participants' satisfaction in the product's appearance (Andersen et al., 2019) and texture (James, 2018). These attributes are essential to determine consumer preferences in chocolate (Sune et al., 2002). Consumers could feel the texture when consuming the 3D printed chocolate. This perception is influenced by varying the infill structure of the construction.

\subsection{Paired preference evaluation}

Figure 15 represents the results of the paired preference test of the 3D printed Choc-1 in 100\% infill and the cast chocolate block, based on textural attribute. No significant difference was identified between the samples as the results indicate that $50 \%$ of participants chose the 3D100\% IP chocolate and 50\% chose the cast samples. This could be because the 3D printed $100 \%$ infill chocolate is perceived to be similar to cast samples with no apparent void existing in the printed chocolate (Mantihal et al., 2019). Besides, participants were also asked to specify their reason for choosing the chocolate samples. Participant mainly indicated that the 3D printed sample was less hard than the cast sample.

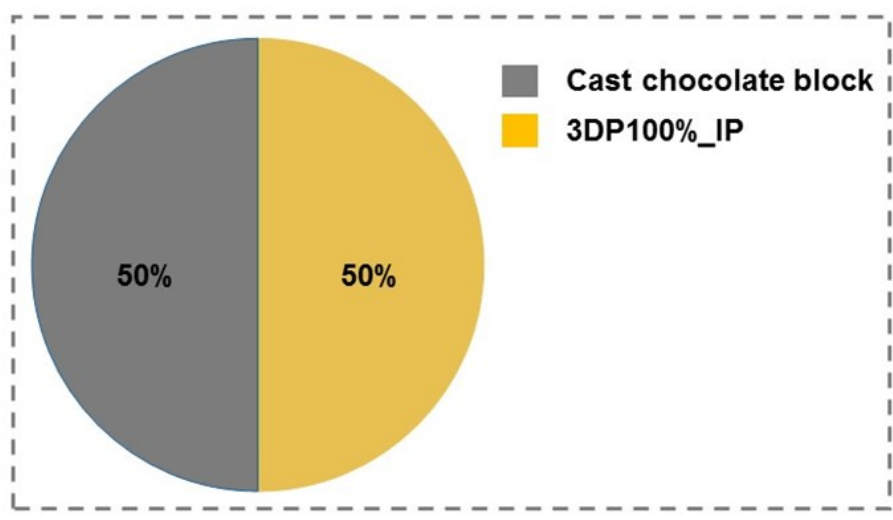

Figure 15. Distribution of the consumer preferences for texture for 3D printed Choc-1 in $100 \%$ infill and cast chocolate block.

In this experiment, the application of 3DFP was successful in fabricating chocolate with different infill percentages, which leads to a textural modification. The 3D printed chocolate attributes (appearance and texture) were appropriate to indicate the participant's perception of the printed product. The outcome from the sensorial experiment was that 3D printed food provided a good impression as participants experienced the real product produced by this new technology. This impression is an indication of a positive perception of a 3D printed food product (Brunner et al., 2018).

\section{Conclusion}

In this study, several modifications to the 3D printer were necessary. A printer bed (that enabled cold water to flow through the built-in tube inside the printer bed) and water circulation system helped to establish an immediate solidification of chocolate, thus supporting the subsequent layering process while building up the 3D construction. An optimal nozzle height for chocolate printing was found to be the same as the nozzle diameter, $0.78 \mathrm{~mm}$. Cross-support was more effective than parallel -support on creating more stable hexagonal-shaped 
constructs. The infill percentage influenced the textural properties of $3 \mathrm{D}$ printed chocolate, signified by an increase in force $(\mathrm{N})$ to break the samples as the infill increased. The results showed that 3D printed chocolates (with 100\% infill) were less hard than cast chocolates, because of a weak interaction of layers, affected by the consecutive layering during extrusion deposition. The sensorial evaluation revealed that appearance has a significant effect on consumer preferences. However, the consumers also indicated their preference (in terms of hardness) for $3 \mathrm{D}$ printed chocolate with $25 \%$ infills. A comparison of a cast chocolate sample with a $100 \%$ infill printed chocolate sample showed an equal preference for both samples, influences in part by their perceived texture. A further exploratory study regarding consumer acceptance of 3DFP should be pursued in terms of various aspects and types of $3 \mathrm{D}$ printed products to enhance consumer acceptance of this novel technology in the domain of the general public.

\section{References}

3D Printing Industry. (2014). History of 3D Printing: The Free Beginner's Guide. Retrieved on August 8, 2018 from 3D printing industry website:http://3dprintingindustry.com/3d-printingbasics-free-beginners-guide/history/. doi.org/10.1007/978-1-4842-0025-4_1

Afoakwa, E.O. (2010). Chocolate science and technology (Vol. 687). Oxford: Wiley-Blackwell. https:// doi.org/10.1002/9781444319880

Andersen, B.V., Brockhoff, P.B. and Hyldig, G. (2019). The importance of liking of appearance, -odour, -taste and -texture in the evaluation of overall liking. A comparison with the evaluation of sensory satisfaction. Food Quality and Preference, 71, 228232. https://doi.org/10.1016/j.foodqual.2018.07.005

Attalla, R., Ling, C. and Selvaganapathy, P. (2016). Fabrication and characterization of gels with integrated channels using 3D printing with microfluidic nozzle for tissue engineering applications. Biomedical microdevices, 18, 17. https://doi.org/10.1007/s10544-016-0042-6

Beckett, S.T. (2011). Industrial chocolate manufacture and use. New Jersey: John Wiley and Sons.

Brunner, T.A., Delley, M. and Denkel, C. (2018). Consumers' attitudes and change of attitude toward 3D-printed food. Food Quality and Preference, 68, 389-396.

https://doi.org/10.1016/ j.foodqual.2017.12.010

Dankar, I., Haddarah, A., El Omar, F., Sepulcre, F. and Pujolà, M. (2018). Assessing the microstructural and rheological changes induced by food additives on potato puree. Food Chemistry, 240, 304-313. https:// doi.org/10.1016/j.foodchem.2017.07.121

Devezeaux de Lavergne, M., Tournier, C., Bertrand, D., Salles, C., van de Velde, F. and Stieger, M. (2016). Dynamic texture perception, oral processing behaviour and bolus properties of emulsion-filled gels with and without contrasting mechanical properties. Food Hydrocolloids, 52, 648-660. https:// doi.org/10.1016/j.foodhyd.2015.07.022

Fernandez-Vicente, M., Calle, W., Ferrandiz, S. and Conejero, A. (2016). Effect of infill parameters on tensile mechanical behavior in desktop 3D printing. $3 D$ printing and additive manufacturing, 3(3), 183192. https://doi.org/10.1089/3dp.2015.0036

Gibson, I., Rosen, D. and Stucker, B. (2010). Additive manufacturing technologies: rapid prototyping to direct digital manufacturing. Boston, USA: Springer. https://doi.org/10.1007/978-1-4419-1120-9

James, B. (2018). Oral processing and texture perception influences satiation. Physiology and Behavior, 193 (Part B), 238-241. https://doi.org/10.1016/ j.physbeh.2018.03.015

Jeltema, M., Beckley, J. and Vahalik, J. (2016). Food texture assessment and preference based on Mouth Behavior. Food Quality and Preference, 52, 160-171. https://doi.org/10.1016/j.foodqual.2016.04.010

Khalil, S. and Sun, W., (2007). Biopolymer deposition for freeform fabrication of hydrogel tissue constructs. Materials Science and Engineering, 27(3), 469478. https://doi.org/10.1016/j.msec.2006.05.023

Lam, C.X.F., Mo, X., Teoh, S.-H. and Hutmacher, D. (2002). Scaffold development using 3D printing with a starch-based polymer. Materials Science and Engineering, 20(1), 49-56. https://doi.org/10.1016/ S0928-4931(02)00012-7

Le Tohic, C., O'Sullivan, J.J., Drapala, K.P., Chartrin, V., Chan, T., Morrison, A.P. and Kelly, A.L. (2018). Effect of 3D printing on the structure and textural properties of processed cheese. Journal of Food Engineering, 220, 56-64. https://doi.org/10.1016/ j.jfoodeng.2017.02.003

Liu, Z., Bhandari, B., Prakash, S. and Zhang, M. (2018). Creation of internal structure of mashed potato construct by 3D printing and its textural properties. Food Research International, 111, 534-543. https:// doi.org/10.1016/j.foodres.2018.05.075

Mantihal, S., Prakash, S. and Bhandari, B. (2019). Textural modification of 3D printed dark chocolate by varying internal infill structure. Food Research International, 121, 648-657. https://doi.org/10.1016/ j.foodres.2018.12.034 
Mantihal, S., Prakash, S., Godoi, F.C. and Bhandari, B. (2017). Optimization of chocolate 3D printing by correlating thermal and flow properties with 3D structure modeling. Innovative Food Science and Emerging Technologies, 44(Supplement C), 21-29. https://doi.org/10.1016/j.ifset.2017.09.012

McLouth, T.D., Severino, J.V., Adams, P.M., Patel, D.N. and Zaldivar, R.J. (2017). The impact of print orientation and raster pattern on fracture toughness in additively manufactured ABS. Additive Manufacturing, 18, 103-109. https://doi.org/10.1016/ j.addma.2017.09.003

Murphy, S.V. and Atala, A. (2014). 3D bioprinting of tissues and organs. Nature biotechnology, 32(8), 773 -785. https://doi.org/10.1038/nbt.2958

Nedomova, S., Trnka, J. and Buchar, J. (2013). Tensile Strength of Dark Chocolate. Acta Technologica Agriculturae, 16(3), 71-73. https://doi.org/10.2478/ ata-2013-0018

Periard, D., Schaal, N., Schaal, M., Malone, E. and Lipson, H. (2007). Printing food. Paper presented at the Proceedings of the 18th Solid Freeform Fabrication Symposium. Austin, Texas, USA.

Rankouhi, B., Javadpour, S., Delfanian, F. and Letcher, T. (2016). Failure analysis and mechanical characterization of $3 \mathrm{D}$ printed $\mathrm{ABS}$ with respect to layer thickness and orientation. Journal of Failure Analysis and Prevention, 16(3), 467-481. https:// doi.org/10.1007/s11668-016-0113-2

Severini, C., Derossi, A. and Azzollini, D. (2016). Variables affecting the printability of foods: Preliminary tests on cereal-based products. Innovative Food Science and Emerging Technologies, 38(Part A), 281-291. https:// doi.org/10.1016/j.ifset.2016.10.001

Sher, D. and Tutó, X. (2015). Review of 3D Food Printing. Temes de disseny, 31, 104-117.

Sun, J., Peng, Z., Zhou, W., Fuh, J.Y., Hong, G.S. and Chiu, A. (2015). A Review on 3D Printing for Customized Food Fabrication. Procedia Manufacturing, 1, 308-319. https://doi.org/10.1016/ j.promfg.2015.09.057

Sune, F., Lacroix, P. and Huon de Kermadec, F. (2002). A comparison of sensory attribute use by children and experts to evaluate chocolate. Food Quality and Preference, 13(8), 545-553. https://doi.org/10.1016/ S0950-3293(02)00057-5

Szczesniak, A.S. (2002). Texture is a sensory property. Food Quality and Preference, 13(4), 215-225. https://doi.org/10.1016/S0950-3293(01)00039-8

Talbot, G. (2009). Science and technology of enrobed and filled chocolate, confectionery and bakery products. USA: Elsevier. https:// doi.org/10.1533/9781845696436

van der Linden, D. (2015). 3D Food Printing. Retrieved on September 24, 2019 from TNO website: https:// www.tno.nl/ media/5517/3d_food_printivanng_march_2015.pdf.

Vancauwenberghe, V., Delele, M.A., Vanbiervliet, J., Aregawi, W., Verboven, P., Lammertyn, J. and Nicolaï, B. (2018). Model-based design and validation of food texture of 3D printed pectin-based food simulants. Journal of Food Engineering, 231, 72-82.

https://doi.org/10.1016/

j.jfoodeng.2018.03.010

Wegrzyn, T.F., Golding, M. and Archer, R.H. (2012). Food Layered Manufacture: A new process for constructing solid foods. Trends in Food Science and Technology, 27(2), 66-72. https://doi.org/10.1016/ j.tifs.2012.04.006

Yang, F., Zhang, M., Bhandari, B. and Liu, Y. (2018). Investigation on lemon juice gel as food material for $3 \mathrm{D}$ printing and optimization of printing parameters. LWT - Food Science and Technology, 87, 67-76. https://doi.org/10.1016/j.lwt.2017.08.054

Zimmerman, A., Walczyk, D.F., Crump, S.S. and Batchelder, J.S. (2012). Additive manufacturing system and method for printing customized chocolate confections. Washington, DC: U.S. Patent and Trademark Office. 